\title{
SYNTHESIS AND PHOTOSENSITIVE PROPERTIES OF UV-CURABLE/ALKALI-SOLUBLE RESIN AS NEGATIVE PHOTORESIST
}

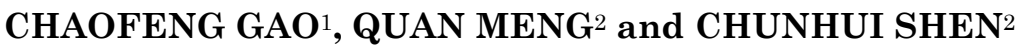

${ }^{1}$ Shaanxi Research Design Institute

of Petroleum and Chemical Industry

Xi'an 710054

P. R. China

${ }^{2}$ Department of Polymer Materials \& Engineering School of Material Science \& Engineering

Wuhan University of Technology

No. 122 Luoshi Road

Wuhan 430070

P. R. China

e-mail: shenchunhui@whut.edu.cn

\begin{abstract}
Novel UV-curable/alkali-soluble resins, named as PA/HEA, BA/HEA, MA/HEA, and HHPA/HEA, were prepared by esterification between 2-hydroxyethylacrylate (HEA) and different acid anhydrides respectively, e.g., phthalic anhydride (PA), succinic anhydride (BA), maleic anhydride (MA), and hexahydrophthalic anhydride (HHPA). The esterification conditions were calculated using the titration of the acid value and the FT-IR. Negative photoresists were prepared by blending AHEA with composite photoinitiators, while the optimal ratio of composite photoinitiators was determined by ultraviolet absorption spectra. The UV-curing process was investigated by FT-IR. It was found that the conversion
\end{abstract}

Keywords and phrases: UV-curable, alkali-soluble, negative photoresist, photosensitive properties.

Received October 30, 2017

(C) 2017 Scientific Advances Publishers 
of double bonds can reach $94.47 \%$ after exposure for $24 \mathrm{~s}$. The effect of photoinitiator on oxygen inhibition (OI) was investigated by ATR-FTIR. The results demonstrated that increasing photoinitiator concentration can produce higher OI resistance. The cured (AHEA) films showed good thermal stability under $150^{\circ} \mathrm{C}$. The PA/HEA and HHPA/HEA films could resist $10 \mathrm{wt} \%$ hydrochloric acid for at least $30 \mathrm{~min}$ but could be stripped in $1 \mathrm{wt} \% \mathrm{NaOH}$ aqueous solution.

\section{Introduction}

Over the past few decades, UV lithography, as one of the most promising technologies available for fabricating micropatterns, has been widely applied in areas such as microelectronics, printed circuit boards, optoelectronics, printing plates, and photo-fabrications [1,2]. In order to meet growing demand, the development of specific functional photoresists is highly desirable, especially for the fabrication of semiconductor devices. Compared with positive photoresist, negative photoresist has the advantages of a lower price and higher resistance to chemical agents, which are beneficial in industrial production. However, conventional negative photoresist will form a cross-linked structure after exposure to irradiation sources, making exposed parts more insoluble during development. Swelling is also a common side-effect of this process, leading to a loss of resolution [3]. On the other hand, cured negative photoresist must be stripped in organic solvents, which can be environmentally damaging.

Hence, the development of new types of negative photoresist has attracted considerable interest. Novolac resins containing pendant carboxyl groups have been prepared by the esterification of 4-hydroxyphenylacetic acid with various alcohols and ethylene glycol monobutyl ether. These novolac resins were then blended with photoacid generator (PAG) to form a negative tone photoresist [4]. Copolymers comprised of glycidyl methacrylate and acrylic acids have been synthesized in methyl ethyl ketone as a solvent via free-radical solution polymerization. In the presence of photogenerated acid, cationic crosslinking of the epoxide 
rings was initiated after exposure to UV radiation. This kind of negative photoresist can also be applied in lithographic printing plates [5]. Functional monomers and monofunctional acrylic rosin derivatives have been synthesized from gum rosin and esterification of maleopimaric acid anhydride and various acrylates, respectively. With the use of trifunctional acrylates or photocrosslinkers, negative patterns can be obtained from rosin derivatives [6].

In this work, a new type of negative photoresist containing monofunctional acrylate with pendant carboxyl groups was prepared by blending with photoinitiators. Compared with other synthesis methods mentioned above, alkali-soluble resin can easily be synthesized by esterification of 2-hydroxyethylacrylate and anhydrides. After exposure to UV light, a linear polymer with functional group can be obtained. With the absence of swelling during development, UV-cured films can easily be stripped in alkali aqueous solution.

\section{Experimental}

\subsection{Materials}

2-Hydroxyethylacrylate (HEA) was kindly supplied by Aladin, Shanghai. Phthalic anhydride (PA), succinic anhydride (BA), maleic anhydride (MA), hexahydrophthalic anhydride (HHPA), and 4-methoxyphenol (MEHQ) were purchased from Sinopharm Chemical Reagent Co. Ltd., China. They were processed to be analytically pure with the use of a polymerization inhibitor. Triphenylphosphine (TPP), a high activity catalyst, was also chemically pure and purchased from Shanghai Guanghua Technology Co. Ltd., China. Three kinds of photoinitiators in photoresist were obtained from Tianjin JiuRi Chemical Co. Ltd. China: 2-methyl-1-[4-(metylthio) phenyl]-2-(4-morpholino)propan-2-one (907), isopropylthioanthraquinone (ITX), and $\alpha$-hydroxy isobutyryl benzene (1173). All were industrial products. The reagents were all used as received. The structures of the four kinds of anhydrides used in the experiment are shown in Figure 1. 
<smiles>O=C1OC(=O)c2ccccc21</smiles>

PA<smiles>O=C1OC(=O)C2CCCCC12</smiles>

HHPA<smiles>O=C1C=CC(=O)O1</smiles>

MA<smiles>O=C1CCC(=O)O1</smiles>

BA

Figure 1. Structures of four kinds of anhydrides used in experiment.

\subsection{Synthesis of UV-curable/alkali-soluble resin}

HEA $(0.2 \mathrm{~mol}, 23.23 \mathrm{~g})$, a small amount of TPP as catalyst (1\%) and MEHQ as inhibitor (0.1wt\%) were added into a $250 \mathrm{~mL}$ three-necked round bottom flask, which was equipped with a thermometer, condenser and mechanical stirrer. Anhydrides $(0.2 \mathrm{~mol})$ was dropped into the solution gradually and stirred at $80^{\circ} \mathrm{C}$ under a nitrogen atmosphere. It was then heated to $90^{\circ} \mathrm{C}$ and kept warm for $2 \sim 3 \mathrm{~h}$; the reaction formula is shown in Figure 2.<smiles>[R]C(=O)C(=O)OCCCOC(=O)C=C</smiles>

Figure 2. Synthesis of UV-curable/alkali-soluble resin.

\subsection{Study of photosensitive properties}

Negative photoresists were prepared by mixing UV-curable/alkalisoluble resin with photoinitiators and then stirred until complete dissolution. The blade was subsequently coated on a clean glass slide to about $30 \mu \mathrm{m}$ thickness. UV-curing of photoresist was carried out at room temperature with UV apparatus equipped with a high-pressure mercury lamp $\left(1 \mathrm{kw}, \lambda_{\max }=365 \mathrm{~nm}\right)$ and a speed-controllable moving belt. Exposure time was controlled by the speed of the moving belt. The 
distance from the lamp to the samples was $15 \mathrm{~cm}$. After irradiation, the cured films were developed in acid solution (hydrochloric acid, 10wt\%) and stripped in alkali solution $(\mathrm{NaOH}, 3 \mathrm{wt} \%)$.

\subsection{Analytical methods and characterization}

\subsubsection{Degree of esterification reaction}

The progress of the esterification reaction was monitored by titration with $0.1 \mathrm{~N} \mathrm{KOH}$ alcoholic solution until the acid value was invariant.

Acid value $(\mathrm{mgKOH} / \mathrm{g})$ was determined by titration with $0.1 \mathrm{~N} \mathrm{KOH}$ alcoholic solution, using thymol blue as the indicator. Samples were taken and dissolved in mixed solution of toluene and absolute alcohol with a volume ratio of $2: 1$. They were then reacted with $\mathrm{KOH}$. Where, $A_{0}$ is the theoretical acid value, $M$ is the total mass at the beginning, $N$ is the number of moles of anhydrides, $A$ is the acid value in the reaction, $C$ and $V$ are the concentration and volume of standard solution in titration respectively. Where, $m$ is mass of sample taken during reaction and $P$ represents the degree of reaction.

$$
\begin{gathered}
A_{0}=\frac{N \times 2 \times 56.11 \times 1000}{M}, \\
A=\frac{C \times V \times 56.11}{m}, \\
P=\frac{A_{0}-A}{1 / 2 A_{0}} .
\end{gathered}
$$

\subsubsection{Characterization of infrared spectra}

IR spectra of four kinds of AHEA system were recorded via a Nicolet170 SX FTIR spectroscopy (Perkin Elmer Co., USA) in the wave number range of $4000-400 \mathrm{~cm}^{-1}$. 
To evaluate the UV-curing process, AHEA resins were coated on $\mathrm{KBr}$ plates and cured with different UV dosages. By monitoring the disappearance of the specific IR absorption band at $1637 \mathrm{~cm}^{-1}$ for the stretching vibration of the $\mathrm{C}=\mathrm{C}$, the chemical conversion of the AHEA systems could be determined.

FTIR spectroscopy (Thermo Nicolet Co., USA) with an attenuated total reflectance (ATR) unit was employed in studying oxygen inhibition (OI) phenomenon appearing in radical polymerization [7]. Cured resins with different concentrations of photoinitiator were pressed against the germanium crystal and the surface was scanned 10 times at a $4 \mathrm{~cm}^{-1}$ resolution to generate FTIR-ATR spectra. The height of the $\mathrm{C}-\mathrm{H}$ absorption peak in double-bond $\left(810 \mathrm{~cm}^{-1}\right)$ was measured for both the uncured $\left(\mathrm{H}_{\text {uncured }}\right)$ and cured $\left(\mathrm{H}_{\text {cured }}\right)$ resins. The degree of conversion (DC) was calculated from the ratio

$$
\mathrm{DC}(\%)=\left(1-\frac{\mathrm{H}_{\text {cured }}}{\mathrm{H}_{\text {uncured }}}\right) \times 100 .
$$

\subsubsection{Viscosity}

Viscosities of different AHEA were performed at $35^{\circ} \mathrm{C}$ on a NDJ-8S digital brookfield rotational viscometer.

\subsubsection{UV absorption spectra}

The absorption spectra of photoinitiators were recorded with an UV/visible spectrophotometer (UV-2550, SHIMADZU, Japan) in the wavelength range of $200 \sim 450 \mathrm{~nm}$. The photoinitiator system 907/ITX with different ratios was dissolved in methyl alcohol with a concentration of $0.01 \mathrm{mg} / \mathrm{mL}$ and then filled by quartz cells with a path length of $1 \mathrm{~cm}$.

\subsubsection{Thermal analysis}

Thermal gravimetric analysis (TGA) was carried out via a thermogravimetric analyzer (STA449C, NETZSCH, Germany) under $\mathrm{N}_{2}$ atmosphere and heated from room temperature to $500^{\circ} \mathrm{C}$ with a heating rate of $10^{\circ} \mathrm{C} / \mathrm{min}$. 


\section{Results and Discussion}

\subsection{Synthesis of UV-curable/alkali-soluble resins}

In this work, novel UV-curable/alkali-soluble resins were prepared by esterification between $\mathrm{OH}$ groups of HEA and different anhydride groups at a certain synthesis conditions. Table 1 lists four kinds of resin prepared by different anhydrides with HEA and the degree of reaction system as calculated. The reaction process was also monitored by acid value. The results demonstrated that different anhydrides under the same synthesis conditions can exhibit different activities when reacting with HEA. The activity diminished as follows: MA $>$ HHPA $>$ BA $>$ PA. Moreover, viscosities of production varied from each other greatly, which can be attributed mainly to the different melting points of anhydrides. Take PA, for example, it is hard to dissolve in the reaction system due to its higher melting point, which makes anhydride group difficult to react with $\mathrm{OH}$ of HEA molecules, subsequently resulting in lower conversion and higher viscosity in all resin.

Table 1. Product of HEA modified by different anhydrides

\begin{tabular}{cccccc}
\hline $\begin{array}{c}\text { Sample } \\
\text { of resin }\end{array}$ & Component & $\begin{array}{c}\text { Reaction } \\
\text { time/h }\end{array}$ & $\begin{array}{c}\text { Terminal acid } \\
\text { value/mgKOH } \mathrm{g}^{-1}\end{array}$ & $\begin{array}{c}\text { Conversion/ } / \\
\%\end{array}$ & $\begin{array}{c}\text { Viscosity } \\
\left(35^{\circ} \mathrm{C}\right) \\
\text { /CP }\end{array}$ \\
\hline 1 & PA/HEA & 3 & 316.83 & 49.16 & 21000 \\
2 & MA/HEA & 3 & 276.12 & 93.42 & 375 \\
3 & BA/HEA & 3 & 301.05 & 82.64 & 2600 \\
4 & HHPA/HEA & 3 & 233.79 & 86.13 & 3710 \\
\hline
\end{tabular}

*Reaction temperature is $90^{\circ} \mathrm{C}$; every resin is cured in the same conditions mentioned above.

The structures were confirmed by FTIR (Figure 3). As seen in the spectra, the absorption peak of hydroxyl group of HEA between $3600 \sim 3200 \mathrm{~cm}^{-1}$ largely decreased due to the reaction with the anhydride groups. This resulted in the formation of a carboxylic acid group in different resins, which exhibited a broad absorbance range between $2500 \mathrm{~cm}^{-1}$ and $3300 \mathrm{~cm}^{-1}$. The absorption peak of double bonds can be 
observed at $1640 \mathrm{~cm}^{-1}$ and $810 \mathrm{~cm}^{-1}$ in all spectra but is seen to slightly weaken from (a) to others. This can be attributed to the partial polymerization of double bonds during the reaction. While small peaks were observed at $1860 \mathrm{~cm}^{-1}$ and $1280 \mathrm{~cm}^{-1}$, indicating the existence of some unreacted anhydride groups in products.

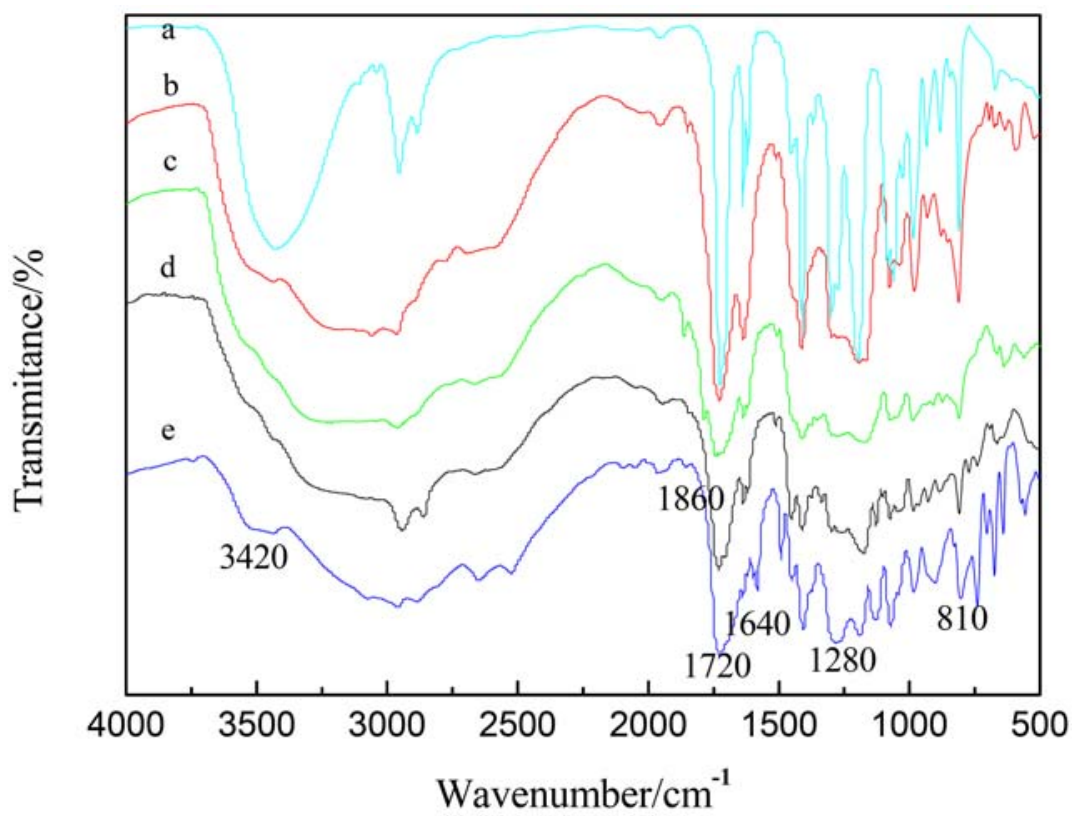

Figure 3. IR spectra of (a) HEA, (b) MA/HEA, (c) BA/HEA, (d) HHPA/HEA, and (e) PA/HEA.

\subsection{Composite 907/ITX photoinitiators}

Activities of photoinitiators have been widely studied in the open literature [8]. In this paper, 907/ITX composite photoinitiators were selected due to their excellent photo initiating performance and good compatibility with resin, especially in colored photosensitive systems. To determine the ratio of 907 to ITX in our experiment, composites photoinitiators were prepared by using different weight ratios of 907/ITX: $2 / 1,3 / 1,4 / 1$. They were then characterized on a UV/visible spectrophotometer. The absorption spectra are shown in Figure 4. 


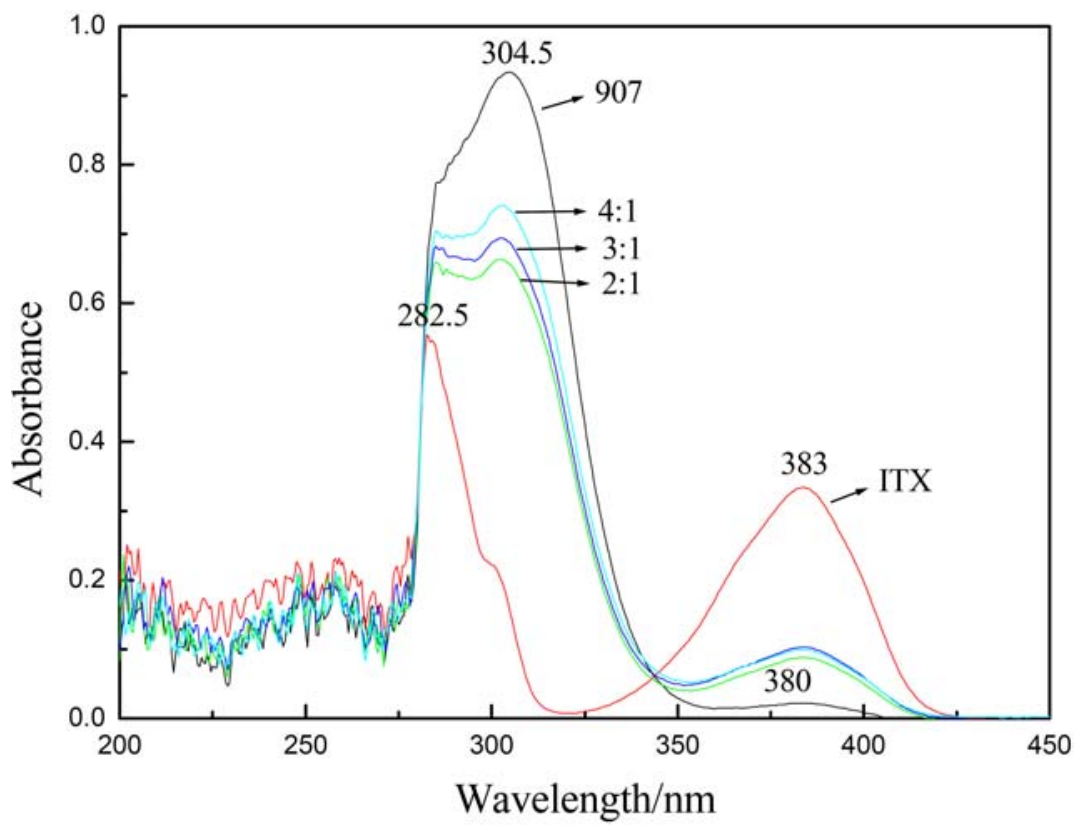

Figure 4. Ultraviolet absorption spectra of 907/ITX composite photoinitiators.

As we can see from Figure 4, absorption peaks of 907 appeared at $304.5 \mathrm{~nm}$ and $380 \mathrm{~nm}$, while ITX owned maximum absorption at $282.5 \mathrm{~nm}$ and 383nm. Composite 907/ITX demonstrated wide absorption between $280 \sim 400 \mathrm{~nm}$. Although the intensity of absorption decreased slightly compared with 907 or ITX, it is still beneficial for the curing of photosensitive prepolymers. In addition, composite 907/ITX showed the highest absorbance when the ratio of 907 to ITX was 4:1; this can be attributed to the synergistic effect between photoinitiator 907 and photosensitizer ITX [9]. Therefore, composite 907/ITX with a 4/1 ratio was selected as the photoinitiator system in our experiment.

Furthermore, HHPA/HEA resin with different contents of composite 907/ITX were prepared and irradiated in the UV apparatus mentioned above, and the energy of complete curing was subsequently captured by the UV energy meter (ORC UV-351, Japan). The results are shown in Table 2. Resin has proven difficult to cure without photoinitiators. With increasing amounts of photoinitiators, more free radicals were produced 
and the photopolymerization of prepolymers was accelerated with relatively low energy. The energy therefore decreased dramatically. When the content was over $3 \mathrm{wt} \%$ of resin, the change of energy was tiny, which was due to the saturation in the concentration of free radicals in prepolymers. Hence, $3 \mathrm{wt} \%$ of the composite photoinitiators did meet demand in the curing process.

Table 2. Effect of the content of photoinitiator on curing behaviour

\begin{tabular}{lcccccc}
\hline $\begin{array}{l}\text { Mass fraction of } \\
\text { photoinitiator/\% }\end{array}$ & 4 & 3 & 2 & 1 & 0.5 & 0 \\
\hline Curing energy/mJ $\cdot \mathrm{cm}^{-2}$ & 206 & 395 & 620 & 1000 & $>1740$ & $\begin{array}{l}\text { Difficult to } \\
\text { cure }\end{array}$ \\
\hline
\end{tabular}

*The ratio of 907 to ITX is $4 / 1$.

\subsection{Study of photosensitive properties}

Four kinds of AHEA containing 3wt\% composite photoinitiators exhibited different photosensitive properties as a consequence of different structures and viscosities. As shown in Table 1, MA/HEA had bad UV-curing behaviour. This can be attributed to the very low viscosity of MA/HEA, which resulted in large gaps between double bonds and made polymerization difficult. Otherwise, BA/HEA was much better than HHPA/HEA and PA/HEA, as there was no bulky phenyl and cyclohexyl to hinder the reaction of double bonds. Figure 5 shows the IR spectra of cured films: (a) HHPA/HEA, (b) PA/HEA, and (c) BA/HEA. Noticeably, the characteristic peaks of double bonds disappeared at $1640 \mathrm{~cm}^{-1}$ and $810 \mathrm{~cm}^{-1}$, indicating the complete curing of these prepolymers. The bond at about $3400 \mathrm{~cm}^{-1}$ can be credited to the stretching vibration of the hydroxyl group. This could be the result of the unreacted HEA participating in polymerization or a small amount of water that absorbed onto cured AHEA in storage because of the presence of polar carboxylic acid groups. Therefore, cured AHEA films should be stored in dry conditions. 


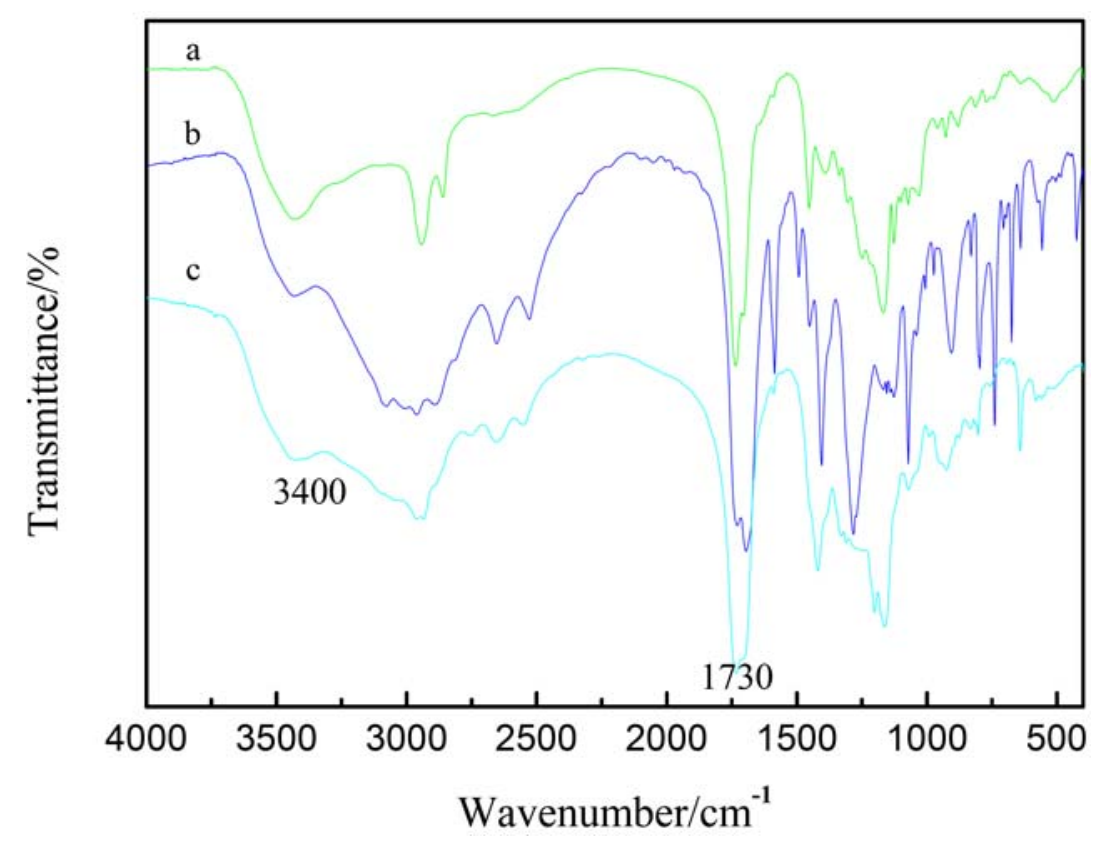

Figure 5. IR spectra of cured film, (a) HHPA/HEA, (b) PA/HEA, and (c) BA/HEA.

\subsection{UV-curing process investigated by the FT-IR spectrum}

HHPA/HEA containing 3wt\% 907/ITX of 4/1 ratio was prepared and UV-cured with varying exposure times controlled by adjusting the speed of moving belt. Five of the selected FT-IR spectra are shown in Figure 6. It can be seen that the intensity of $\mathrm{C}=\mathrm{C}$ in stretching vibration absorption at $1637 \mathrm{~cm}^{-1}$ diminished as acrylic ester prepolymer was converted to polymer. Several invariant peaks also were also displayed in the spectra. The experimental procedures for spectrometric measurements were strictly controlled to keep the absorption of the peaks stable. The absorption of cyclohexyl in HHPA/HEA at $1030 \mathrm{~cm}^{-1}$ $\left(\mathrm{A}_{1030}\right)$ could serve as an internal standard to normalize the polymer spectra. As a result, the area of peak at $1637 \mathrm{~cm}^{-1}\left(\mathrm{~A}_{1637}\right)$ could be converted into relative values, and the conversion of double bonds (DC) 
was calculated from the following equation by relative values with various exposure times $(t)$ :

$$
\mathrm{DC} \%=\frac{\left(\mathrm{A}_{1637} / \mathrm{A}_{1030}\right)_{0}-\left(\mathrm{A}_{1637} / \mathrm{A}_{1030}\right)_{t}}{\left(\mathrm{~A}_{1637} / \mathrm{A}_{1030}\right)_{0}} \times 100 \% .
$$

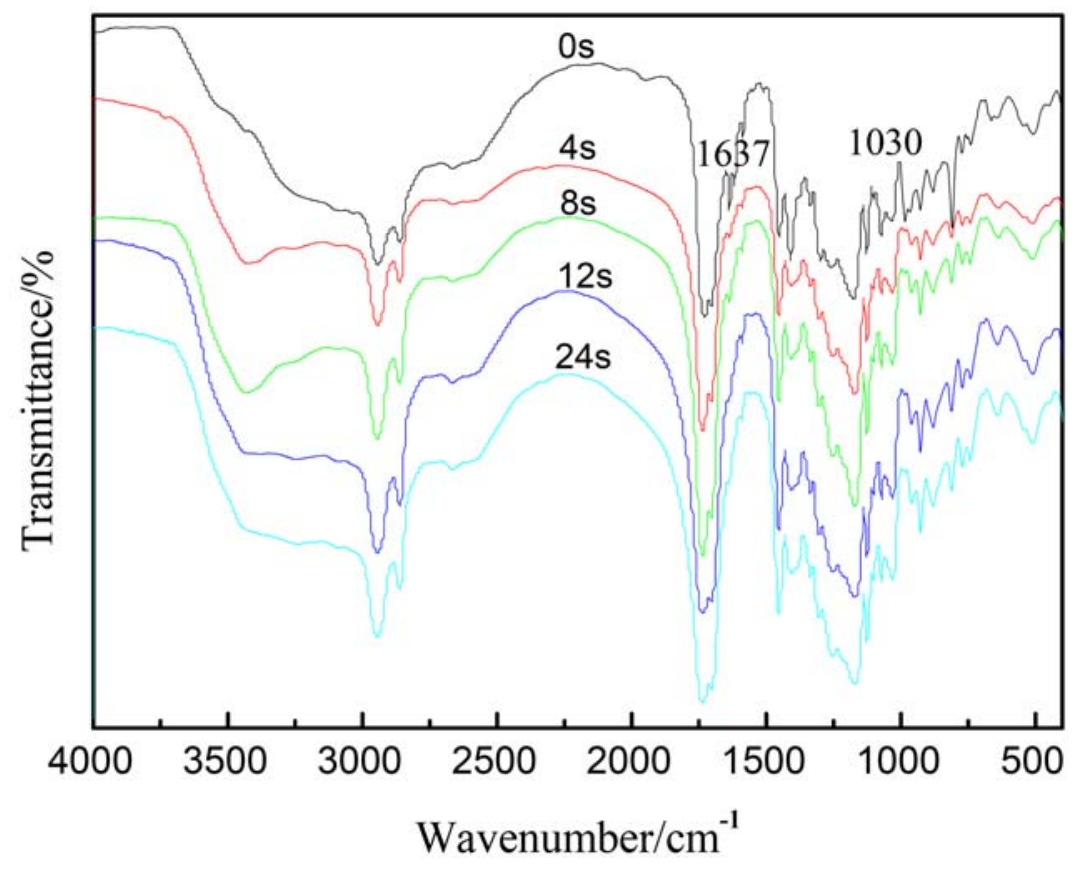

Figure 6. IR spectra of HHPA/HEA cured film in different exposure times.

Table 3 lists areas of peaks at $1637 \mathrm{~cm}^{-1}$ and $1030 \mathrm{~cm}^{-1}$. Upon increasing the exposure time from $0 \mathrm{~s}$ to $4 \mathrm{~s}$, the conversion of double bonds increased by about 50\%, which indicated that the photosensitive system was highly reactive in UV light. After exposure for $24 \mathrm{~s}$, conversion could reach $94.47 \%$. This clearly demonstrated correlation between the rapidly increasing conversion rate in the early stage of exposure and the slow growth after exposure for $12 \mathrm{~s}$. This can be mainly attributed to the concentrations of double bonds dropping off while undergoing polymerization; this increases the probability of coupling 
termination of radicals. Thus, it is evidently undesirable to promote the photocuring degree by extending exposure time merely with a certain concentration of photoinitiators.

Table 3. Conversion of carbonate double bond in different exposure time

\begin{tabular}{ccccc}
\hline $\begin{array}{c}\text { Exposure time } \\
\mathrm{t} / \mathrm{s}\end{array}$ & $\mathrm{A}_{1637}$ & $\mathrm{~A}_{1030}$ & $\left(\mathrm{~A}_{1637} / \mathrm{A}_{1030}\right)_{t}$ & $\mathrm{DC}(\%)$ \\
\hline 0 & 86.003 & 206.675 & $41.61 \%$ & 0 \\
4 & 52.637 & 256.189 & $20.55 \%$ & 50.61 \\
8 & 44.867 & 375.814 & $11.94 \%$ & 71.30 \\
12 & 29.310 & 439.105 & $6.67 \%$ & 83.97 \\
24 & 10.527 & 456.671 & $2.31 \%$ & 94.47 \\
\hline
\end{tabular}

\subsection{Effect of photoinitiator on oxygen inhibition}

It is well known that OI is a common phenomenon in polymerization triggered by free radicals [10], which can result in a tacky surface with poor mechanical properties. In this work, resins HHPA/HEA with different concentrations of photoinitiator 1173 were cured in atmosphere and the effect of photoinitiator on OI was investigated by ATR-TTIR. The results are shown in Figure 7. Peak at $810 \mathrm{~cm}^{-1}$ is the characteristic absorbance of $\mathrm{C}-\mathrm{H}$ of double bonds, which showed weakening intensity with increasing concentration of photointiator 1173. 


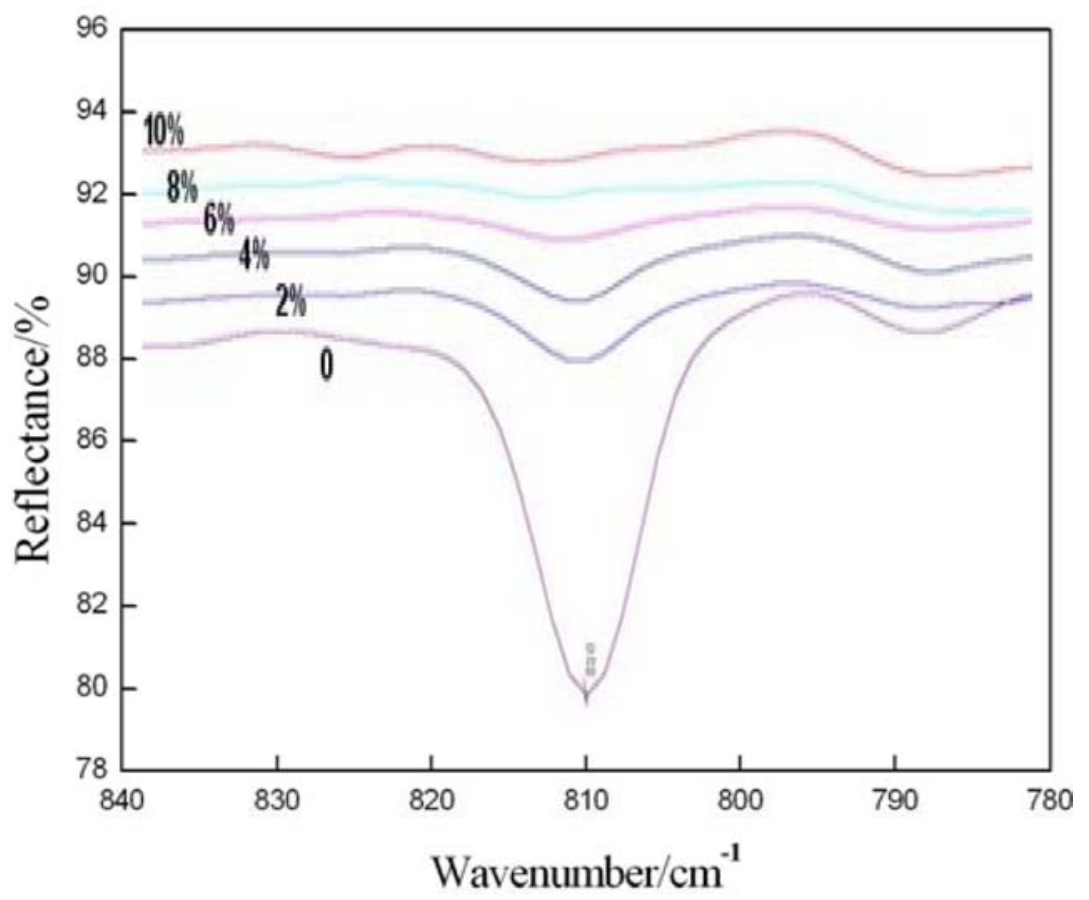

Figure 7. ATR-FTIR spectra of cured film with different concentrations of the photointiator 1173 .

This indicates that a higher content of photoinitiator can lead to higher conversion of double bonds on the surface of the film and less influence caused by oxygen inhibition. The conversion values were calculated in accordance with formula (4) and are shown in Figure 8. In a lower content of photoinitiator ( $2 \mathrm{wt} \%$ ), DC for the film surface was found to be $80.72 \%$. DC however, could achieve about $96 \%$ when the content increased to $8 \mathrm{wt} \%$ and was kept almost equivalent in $10 \mathrm{wt} \%$. Therefore, increasing the concentration of photoinitiator has shown to be an effective method in producing higher OI resistance. 


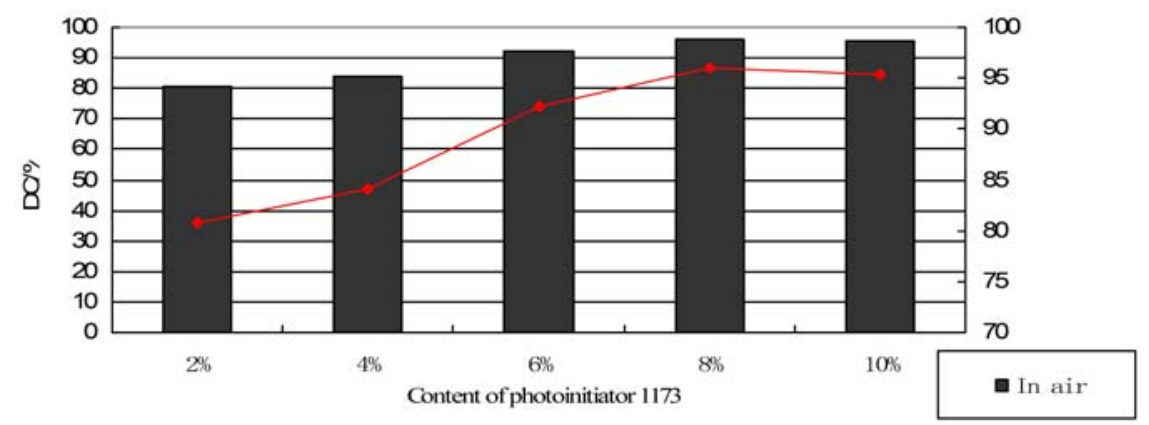

Figure 8. DCs of cured film surface with different concentrations of photoinitiator 1173.

\subsection{Thermal stability}

As illustrated in Figure 9, the thermal stability of different UV-cured coatings was evaluated by the weight loss thermograms recorded in $\mathrm{N}_{2}$ atmosphere. From $35^{\circ} \mathrm{C}$ to $150^{\circ} \mathrm{C}$, different UV-cured films have a weight loss of about $3 \% \sim 5 \%$. This can be attributed to the evaporation of moisture absorbed by hydrophilic carboxyl groups. Weight loss in cured PA/HEA and HHPA/HEA films was slightly lower than that of BA/HEA film, mainly because BA/HEA system has a higher yield and more carboxyl groups. Mass weight loss occurred at around $150^{\circ} \mathrm{C}$ due to the decomposition of ester groups and unreacted HEA including anhydrides. It is therefore evident that cured films of products can be applied well under $150^{\circ} \mathrm{C}$ but should be kept in dry conditions. 


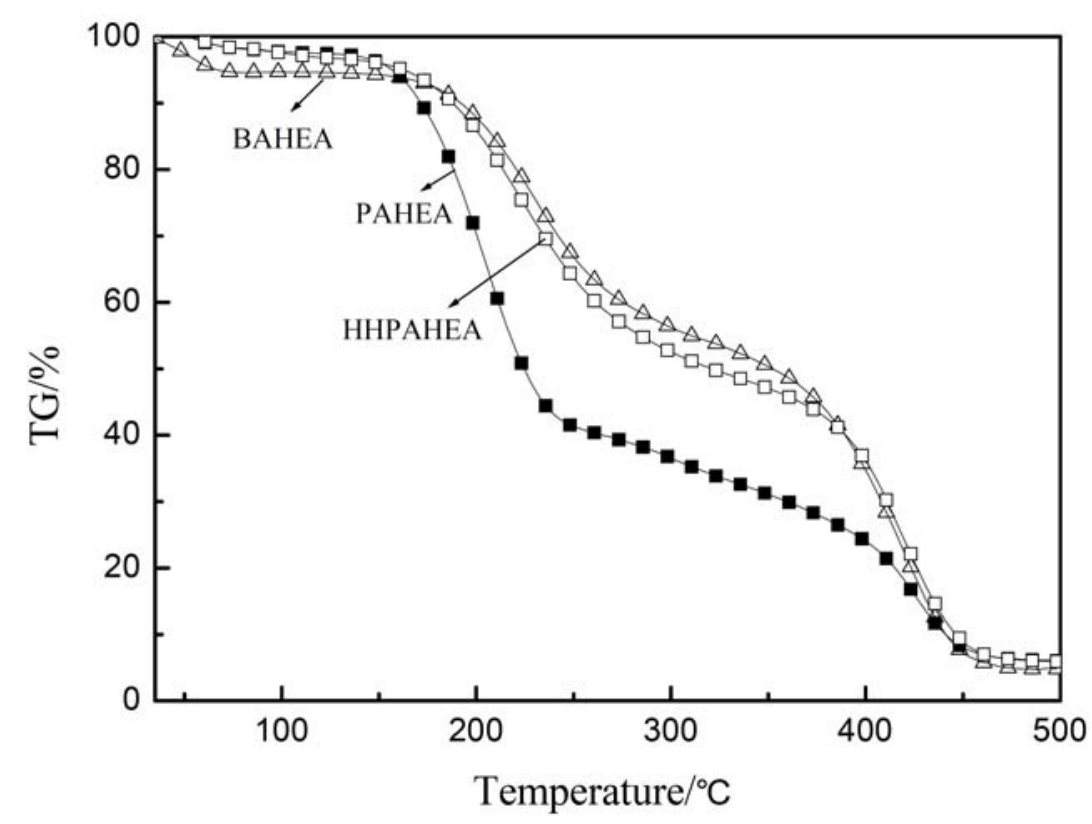

Figure 9. TG curves of different cured films.

\subsection{Acid resistance}

Good resistance to acid is one of the main advantages of photoresist in the etching process of semiconductors such as ITO. The cured photoresist can thus protect semiconductors from etching by strong acid like hydrochloric acid. In this work, 10wt\% hydrochloric acid was selected to evaluate the property of acid resistance at room temperature of about $27^{\circ} \mathrm{C}$. Different cured films were prepared in the same UV dosage and immersed in acid; the results are shown in Figure 10. After 5min, BA/HEA cured film was partially stripped from glass substrate. PA/HEA and HHPA/HEA were able to keep the film smooth and of integrity for at least 30min. After 60min, cured HHPA/HEA film began wrinkling, far ahead of PA/HEA film. This could be related to the strong adhesive force associated with substrates and the excellent surface hardness of PA/HEA and HHPA/HEA resulting from the presence of the benzene ring and cyclohexyl. 

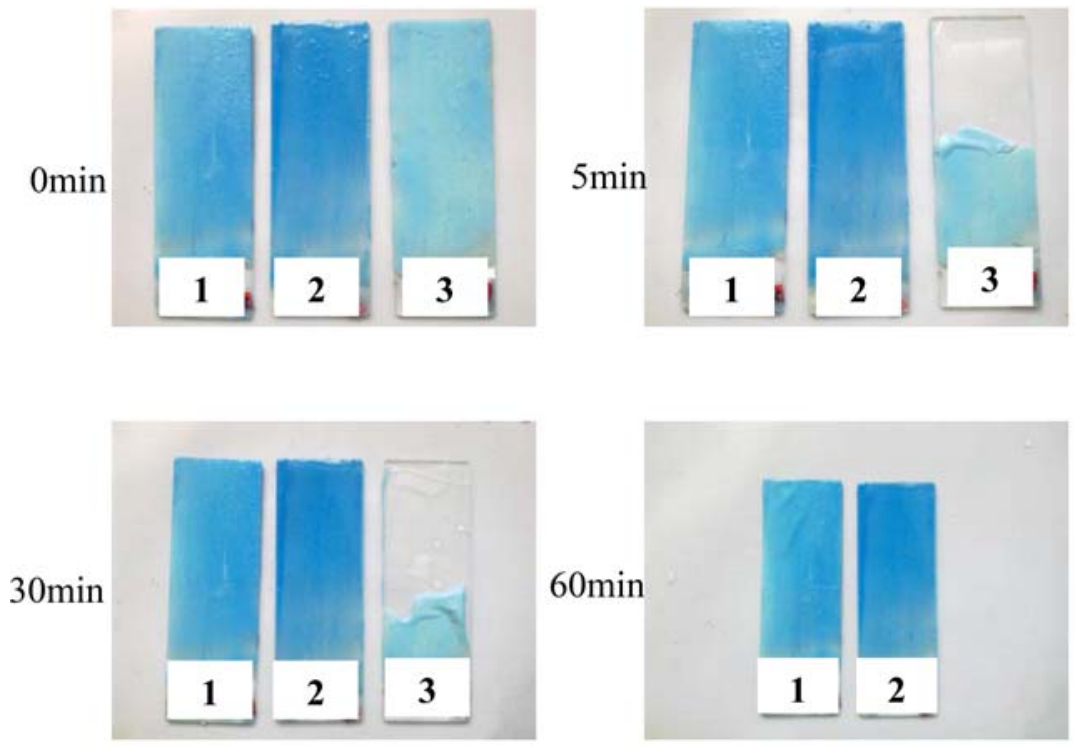

Figure 10. Acid resistance of UV cured film on glass in different system (1) HHPA/HEA, (2) PA/HEA, and (3) BA/HEA.

\subsection{Stripping film in alkali aqueous solution}

Good properties for stripping film after the etching process can earn more time to promote industrial productivity. Lower concentrations of alkali aqueous solution and a shorter time span represent advantageous properties for stripping. Different cured films were immersed in 1wt\% $\mathrm{NaOH}$ aqueous solution at room temperature. The results of stripping after 2 min without any external forces are shown in Figure 11. The under part without immersion was treated as a matched group. As can be seen from the picture, BA/HEA film was stripped faster than PA/HEA and HHPA/HEA film in alkali solution. This can be attributed to the lower adhesive force of BA/HEA with substrate and more carboxyl groups, making alkali aqueous react more easily with polar carboxyl group and leading to the stripping of substrates. 


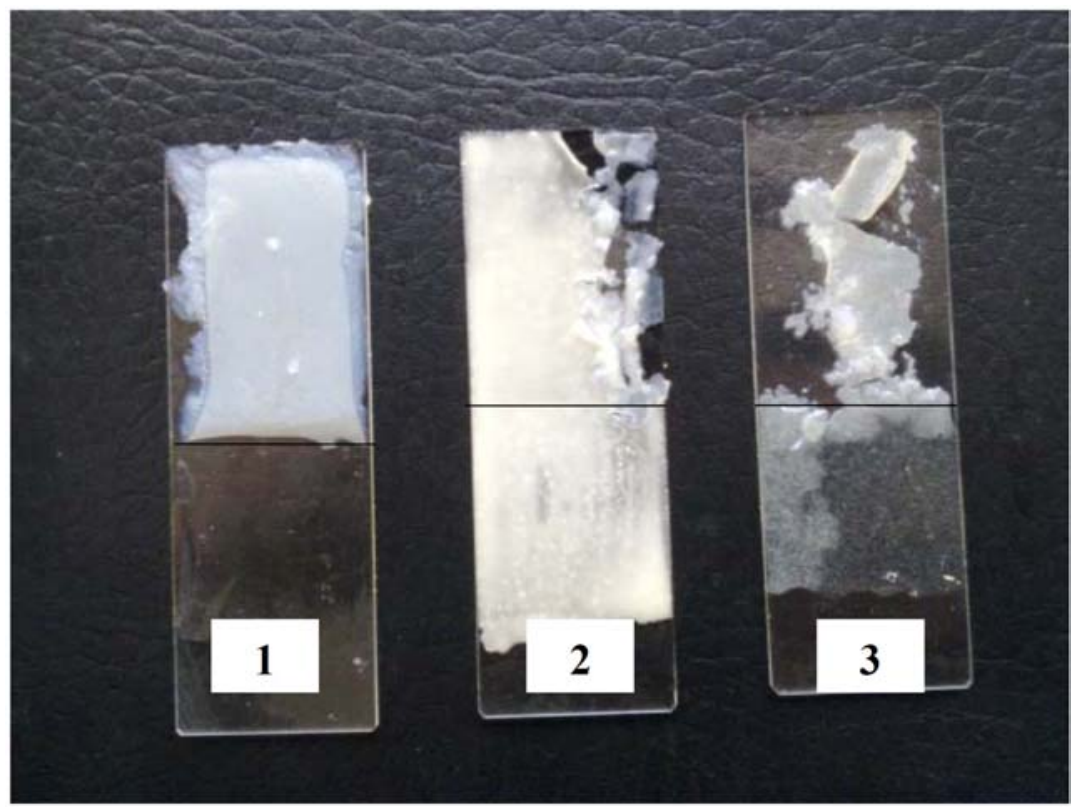

Figure 11. Property of stripping film in $\mathrm{NaOH}$ aqueous solution (1) HHPA/HEA, (2) PA/HEA, and (3) BA/HEA.

\section{Conclusion}

Different UV-curable/alkali-soluble resins were prepared by esterification between the $\mathrm{OH}$ groups of HEA and anhydrides. The conversion of reaction diminished as follows: MA $>$ HHPA $>$ BA $>$ PA. Before performing the UV curing experiment, 907/ITX composite photoinitiators were selected and the ratio of 907 to ITX was determined by ultraviolet absorption spectra. The optimal was identified as 4:1. The UV-curing process was investigated by FT-IR spectrum; conversion of the double bonds was shown to jump dramatically in the early stage and could reach $94.47 \%$ after exposure for $24 \mathrm{~s}$. The effect of photoinitiator on OI was investigated by ATR-TTIR. It was evident that increasing the concentration of photoinitiator was effective in producing a higher OI resistance. The cured films possessed good thermal stability under $150^{\circ} \mathrm{C}$; 
PA/HEA and HHPA/HEA could resist 10wt\% hydrochloric acid for at least $30 \mathrm{~min}$ and strip the film in $1 \mathrm{wt} \% \mathrm{NaOH}$ aqueous solution. From the above, it can be concluded that HHPA/HEA would be more highly appropriate as a main resin in negative photoresist.

\section{References}

[1] L. E. Schmidt, S. Yi, Y. H. Jin, Y. Leterrier, Y. H. Cho and J. A. E. Manson, J. Micromech. Microeng. 18 (2008), 045022;

\section{DOI:10.1088/0960-1317/18/4/045022.}

[2] R. Yang, S. A. Soper and W. Wang, Sens. Actuators A 135 (2007), 625-636.

[3] M. Sharma, A. A. Naik, M. Gaur, P. Raghunathan and S. V. Eswaran, J. Chem. Sci. 121 (2009), 503-508.

[4] H. H. Liu, W. T. Chen and F. T. Wu, J. Polym. Res. 9 (2002), 251-256.

[5] A. M. El-Demerdash and W. A. Sadik, J. Appl. Polym. Sci. 118 (2010), 1933-1942.

[6] J. S. Lee and S. I. Hong, Eur. Polym. J. 38 (2002), 387-392.

[7] L. Feng and B. I. Suh, J. Appl. Polym. Sci. 112 (2009), 1565-1571.

[8] K. Dietliker, R. Husler, J. Birbaum, S. Ilg, S. Villeneuve, K. Studer, T. Jung, J. Benkhoff, H. Kura and A. Matsumoto, Prog. Org. Coat. 58 (2007), 146-157.

[9] H. Q. Xie, X. G. Zhan and D. Xie, J. Appl. Polym. Sci. 98 (2005), 1607-1614.

[10] R. F. Bartholomew and R. S. Davidson, Part I, J. Chem. Soc. (1971), 2342-2346. 